\title{
Growth Hormone Deficiency: Strategies and Indications to Continue Growth Hormone Therapy in Transition from Adolescence to Adult Life
}

\author{
Gary M. Leonga Gudmundur Johannsson ${ }^{\mathrm{b}}$ \\ aPituitary Research Unit, Garvan Institute of Medical Research, St Vincent's Hospital, Sydney, NSW, Australia; \\ ${ }^{b}$ Research Centre for Endocrinology and Metabolism, Sahlgrenska University Hospital, Göteborg, Sweden
}

\author{
Key Words \\ Growth hormone - Growth hormone deficiency • \\ Transition - Adolescence - Metabolism - Bone - Quality of \\ life $\cdot$ Retesting $\cdot$ Discontinuation
}

\begin{abstract}
The most common practice in children with growth hormone $(\mathrm{GH})$ deficiency is to discontinue $\mathrm{GH}$ treatment in adolescence after attainment of final height. Childhoodonset $\mathrm{GH}$ deficiency (GHD) that continues into adulthood and is not treated may be associated with more severe consequences than GHD acquired as an adult. This raises the question of the importance of $\mathrm{GH}$ for continuing tissue maturation after longitudinal growth has stopped. Data from recent studies suggest that muscle and bone maturation is arrested when $\mathrm{GH}$ treatment is discontinued at final height in adolescents in whom severe GHD continues into adulthood. These patients also develop, even in the short term, well-known cardiovascular risk factors associated with GHD in adults. Retesting for GHD is crucial in adolescence because a considerable number of patients will not have severe GHD according to the criteria set for adults. Continuing replacement therapy in these patients is warranted, but cost-benefit comparisons of treatment are still under debate and a lack of acceptance, and hence reimburse-
\end{abstract}

ment, for such treatment is still common. In this review, the management and organization of transition, with and without continuing $\mathrm{GH}$ replacement therapy, are also discussed.

Copyright $\odot 2003$ S. Karger AG, Basel

\section{Introduction}

Transition is a term used to describe the period of adolescence after which the primary goal of growth hormone $(\mathrm{GH})$ treatment is to achieve final adult height, and when the major goals of $\mathrm{GH}$ replacement become normalization of metabolism and quality of life. Data on somatic development from studies of this period are scarce. This is also the period when paediatric endocrinologists have to support their patients' entry into the adult world, and adult endocrinologists have to gain the confidence of these new patients and their paediatric endocrinologist.

The literature about transition has been characterized by a lack of information on GH doses, how GH treatment should be targeted, and uncertainties regarding the overall benefits of adult GH replacement therapy. Lack of communication between the paediatric and adult endocrine settings and lack of organized caring for these patients is common. There are, therefore, both clinical and practical problems during the period of transition.

\begin{tabular}{ll}
\hline KARGER & ( ) 2003 S. Karger AG, Basel \\
0301-0163/03/0607-0078\$19.50/0 \\
$\begin{array}{l}\text { Fax +4161306 12 34 } \\
\begin{array}{l}\text { E-Mail karger@karger.ch } \\
\text { www.karger.com }\end{array}\end{array}$ & $\begin{array}{l}\text { Accessible online at: } \\
\text { www.karger.com/hre }\end{array}$
\end{tabular}

Dr. G. Johannsson

Research Centre for Endocrinology and Metabolism

Sahlgrenska University Hospital

SE-413 45 Göteborg (Sweden)

Tel. +46 31 603101, Fax +46 31 821524, E-Mail Gudmundur.Johannsson@medic.gu.se 
The period from the attainment of final adult height to the age of 25 to 30 years is probably of importance for tissue maturation. Data suggest that peak bone mass, and peak muscle mass and strength are obtained during this period of life [1, 2]. Psychosocial maturation is also important during this stage of life. The reason for increasing interest in this period in adolescents with GH deficiency (GHD) is the realization of the consequences of untreated GHD in hypopituitary adults. These include a two-fold increase in cardiovascular and cerebrovascular mortality compared with the background population [3, 4]. Patients have a number of important cardiovascular risk factors and reduced quality of life and well-being that respond to GH replacement therapy [5-8]. The conclusion has therefore been reached that continuing $\mathrm{GH}$ replacement therapy may be needed after final height has been attained.

In this short review, we discuss the consequences of not receiving adult $\mathrm{GH}$ replacement therapy in patients with childhood-onset (CO) GHD, the short-term consequences of discontinuing $\mathrm{GH}$ treatment after final height is reached, and the current understanding of how to define GHD in late adolescence.

\section{Adults with Childhood-Onset GH Deficiency}

The majority of cross-sectional studies of GHD in adults have not analysed patients with CO GHD separately from those with adult-onset (AO) disease, and some studies have only included one of the two groups [5, 6, 9, 10]. It has been suggested, however, that the appearance of GHD may differ between individuals with $\mathrm{CO}$ and AO disease [11]. In direct comparison with patients with $\mathrm{AO}$ GHD, patients with CO GHD have a lower body mass index, waist:hip ratio, serum insulin-like growth factor I (IGF-I) concentrations and higher serum high-density lipoprotein (HDL) cholesterol concentrations, as well as superior (better) scores for quality of life [11]. In addition, results from trials that have included mainly patients with either $\mathrm{CO}$ or AO GHD have indicated more severe consequences of GHD in adults with CO disease in terms of reduced muscle mass $[9,12]$ and bone mass $[13,14]$. The consequences of GHD, in terms of heart structure and function, may also be more pronounced in adults with $\mathrm{CO}$ GHD [15]. If, however, the AO and CO groups are closely matched in terms of age, sex, height and body weight, then both groups have similar degrees of impairment in left ventricular function [16]. Moreover, the apparent differences in body composition at baseline between individ- uals with $\mathrm{CO}$ and AO GHD were explained in one study by lower body height in those with CO disease [17]. In another study, the difference in serum IGF-I concentration between the groups was found to be eliminated if there was adjustment for estimated duration and severity of GHD [18]. The immediate discontinuation of $\mathrm{GH}$ treatment after final height is reached, but before peak bone mass and other tissue maturation have been achieved, may explain some of the differences found between patients with $\mathrm{CO}$ and AO GHD [19-21].

The response to GH replacement therapy may be different in adults with $\mathrm{CO}$ and $\mathrm{AO}$ disease. The first study to investigate this possibility did not demonstrate differences in the response to GH, in terms of IGF-I and body composition, when baseline differences between groups were adjusted [17]. In a large multi-centre trial, patients with CO GHD were shown to have normal scoring on a quality of life questionnaire at baseline and it was found that their scoring did not change in response to GH treatment [11]. In a recent trial, patients with $\mathrm{CO}$ or AO GHD were selected and closely matched in terms of age, sex, body mass index and degree of anterior pituitary hormone deficiency [21]. Although closely matched, the $\mathrm{CO}$ group was found to have a longer duration of hypopituitarism, to be shorter, have reduced serum concentration of IGF-I, increased total body fat, decreased lean body mass and reduced muscle strength. In addition, bone mineral content (BMC) and bone mineral density (BMD) in the lumbar spine were reduced in the $\mathrm{CO}$ group whereas the patients with $\mathrm{AO}$ disease had increased serum concentration of total cholesterol. In response to 5 years of GH replacement therapy, the $\mathrm{CO}$ group showed a greater increase in lean body mass, muscle strength, BMC and BMD in the lumbar spine, while the $\mathrm{AO}$ group had a greater reduction in total serum cholesterol. After 5 years of GH replacement, there were no differences between the two study groups after a correction for body height, indicating that all differences between the two groups at baseline could be corrected through long-term GH replacement therapy.

\section{Consequences of Discontinuing GH Treatment in Adolescents}

The prospective consequences of discontinuing $\mathrm{GH}$ treatment in adolescents after final height has been achieved have not often been studied. In the first trial conducted, involving eight adolescent patients, reductions in quadriceps muscle strength, muscle size and muscle fibre area were demonstrated, as well as an increase in the 


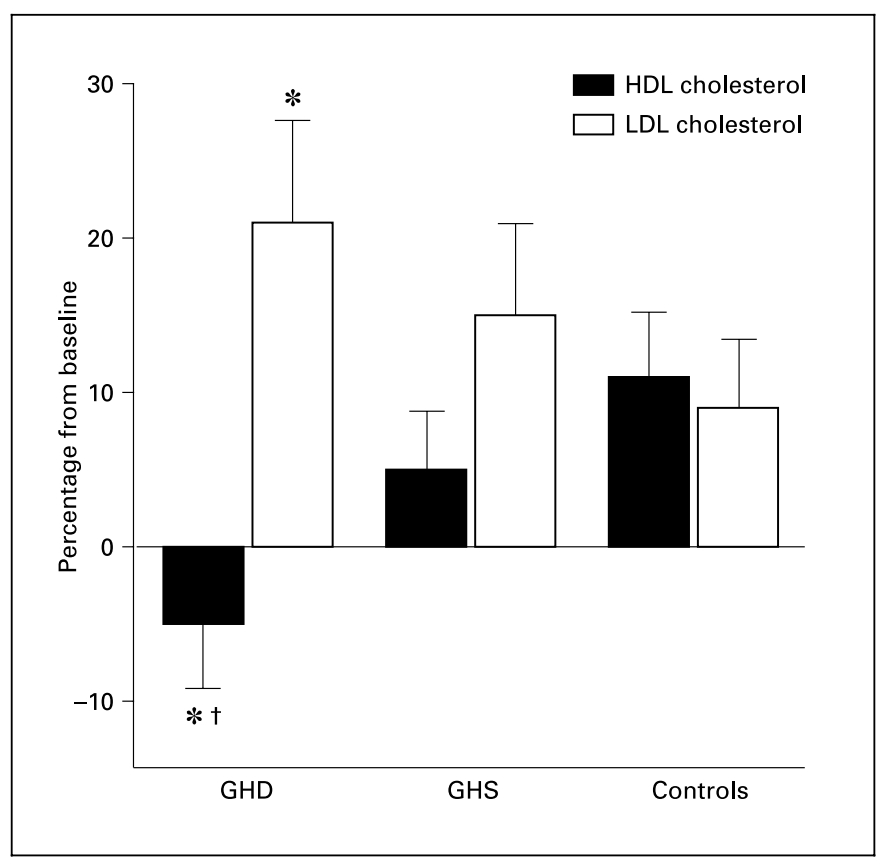

Fig. 1. Percentage change in serum LDL-cholesterol and HDL-cholesterol concentrations between baseline and 2 years after discontinuing GH treatment in adolescents. One group consisted of 21 adolescents with severe GHD, the second group included $19 \mathrm{GH}$-sufficient adolescents (GHS) and the third group consisted of 16 healthy controls. $* p<0.05$ compared with controls and ${ }^{\dagger} \mathrm{p}<0.05$ compared with the GH-sufficient group. Data from Johannsson et al. [25].

amount of body fat after 12 months without GH treatment [22]. In a second study, increased fat mass was seen in six patients with continuing GHD, but not in 10 patients classified as having normal somatotropic function 12 weeks after the discontinuation of GH treatment [23]. A similar finding was reported in eight adolescents followed for 12 months after GH treatment was stopped [24].

A more recent trial evaluated 40 adolescent patients before and annually for 2 years after stopping GH treatment once final height was reached [25]. Sixteen people were recruited to be healthy controls and were followed longitudinally for 2 years for comparison. All participants entering the trial were re-evaluated in terms of severe GHD and 19 patients were classified as GH sufficient. The GH-sufficient group and the controls displayed longitudinal changes in terms of lipoproteins and body composition similar to those reported in large cross-sectional cohorts of healthy individuals of a similar age [26, 27]; this indicated that the endogenous GH secretion in the $\mathrm{GH}$-sufficient group was adequate during the period of follow-up.
Total cholesterol, low-density lipoprotein (LDL) cholesterol and apolipoprotein B levels were higher in the GH-deficient group than in the GH-sufficient and control groups, and serum concentrations of HDL-cholesterol decreased in the GH-deficient group, but increased in the other two groups [25] (fig. 1). Moreover, the amount of total body fat and abdominal fat mass increased more markedly in the GH-deficient group than in the GH-sufficient and control groups when GH treatment was discontinued. Blood glucose levels did not change in the adolescents in whom GH treatment was stopped or in the controls during 2 years of observation, and the level of glycosylated haemoglobin and concentration of serum insulin decreased in both patient groups [25].

In a randomized trial of either discontinuing (placebo) or continuing $\mathrm{GH}$ treatment after final height was reached, rates of fasting lipid oxidation decreased and glucose oxidation and body fat mass increased in those participants receiving 12 months of placebo treatment, but not in those who continued GH therapy [28, 29]. These changes were reversed after resumption of GH treatment. Using a euglycaemic glucose clamp, a tendency of insulin sensitivity to improve was seen when GH treatment was changed to placebo and a decrease was observed when GH treatment was reintroduced; however, no change was observed in the group that continued GH treatment [29].

These studies of transition have also produced data suggesting that $\mathrm{GH}$ is of importance for the maturation of lean body mass and muscle strength in adolescents and young adults [30]. Two hundred and twenty-three healthy adolescents were randomly selected for prospective measurements of lean body mass and handgrip strength between the ages of 17 and 21 years. Their lean body mass and handgrip strength increased over the 2-year study period, but this increase was not seen in a group of 21 GH-deficient adolescents who were not receiving GH treatment (fig. 2). Recent data also demonstrate that discontinuation of $\mathrm{GH}$ treatment in adolescents at final height impairs cardiac morphology and function [31]. In an open study of 10 adolescents with severe GHD continuing into adulthood, discontinuation of GH treatment was seen to reduce left ventricular diastolic performance and left ventricular mass index after 6 months. Both parameters returned to baseline levels 6 months after $\mathrm{GH}$ replacement therapy was restarted.

There is concern that patients receiving GH treatment during childhood who have GHD into adulthood may not achieve peak bone mass as a consequence of discontinuing $\mathrm{GH}$ treatment at final height $[13,19]$. Comparative studies with $\mathrm{CO}$ and $\mathrm{AO}$ patients who are closely matched 
(except for height) show that the $\mathrm{CO}$ group had reduced BMD, suggesting that peak bone mass was not attained or that there may have been significant bone loss after GH treatment was discontinued $[20,21]$. It was found in a recent trial, however, that adolescents with continuing GHD into adulthood had the same BMC and BMD as a small well-matched control group at the time of discontinuation of $\mathrm{GH}$ treatment [32]. After GH therapy was stopped, a further increase in BMD and a sharp reduction in serum markers of bone formation and bone resorption occurred in line with previous experience in young adults stopping GH treatment [33] and most probably reflecting a reduction in bone turnover and mineralization of the bone-remodelling units. In a recent abstract, however, data demonstrating that adolescents who continue GH treatment achieve more marked increases in total BMC than those who discontinue treatment suggest that discontinuation may limit the attainment of peak bone mass [34].

Scoring of quality of life from commonly used generic questionnaires is normal in adolescents with CO GHD $[11,35]$. The scoring has, however, been observed to be slightly poorer in a group with severe GHD continuing into adulthood, in terms of depression, general health and anxiety, compared with adolescents who did not have severe GHD at final height [35]. No further changes occurred during the 2 years after $\mathrm{GH}$ treatment was stopped, demonstrating that discontinuing GH therapy in late adolescence does not risk an immediate decline in perceived quality of life detectable with the Nottingham Health Profile and Psychological General Well-Being measures. Using The Mood Adjective Check List and visual analogue assessments, however, small temporal changes occurred, suggesting clinically significant changes [35]. It is also clear from recent data that the $\mathrm{CO}$ group is not homogeneous in terms of perceived well-being and quality of life. In an open trial of individualized GH dose titration, CO patients in whom quality of life was impaired at baseline showed a capacity for improvement that was equal or even greater than that of patients with AO GHD [36].

\section{Retesting for Continuing Severe GH Deficiency into Adulthood}

Retesting of GH response to various pharmacological stimuli in late adolescence or young adulthood in patients with CO GHD has revealed a significant but variable proportion of patients (from 12 to 90\%) with normal GH

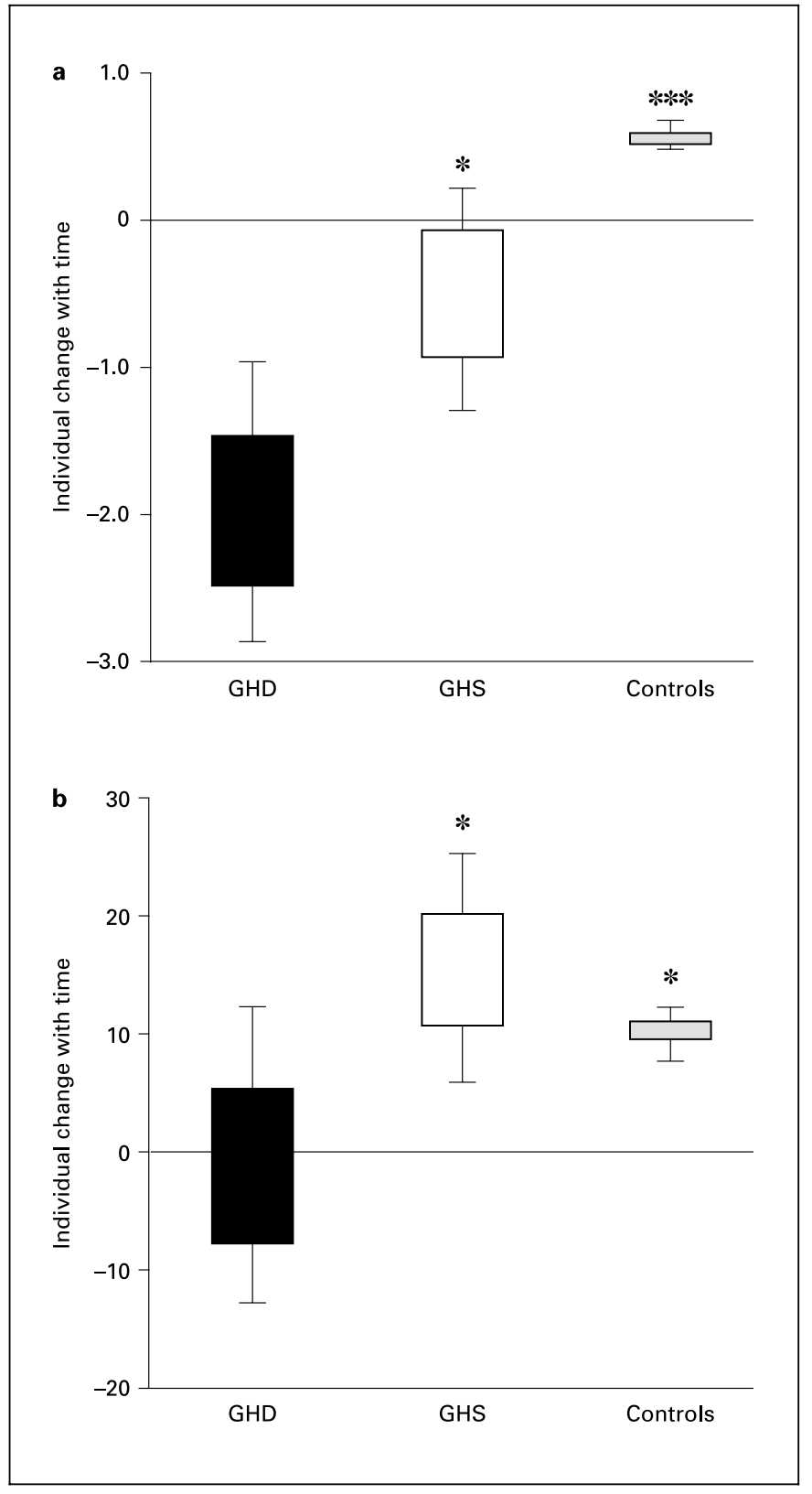

Fig. 2. Box plot showing mean ( \pm standard error of the mean and \pm standard deviation [bars]) individual change in a lean body mass and b peak hand grip strength in adolescents discontinuing GH treatment and healthy controls of similar age followed for 2 and 4 years, respectively. The three groups examined were 21 adolescents with GHD continuing into adulthood, $19 \mathrm{GH}$-sufficient adolescents (GHS) and 223 adolescent controls. The data are shown as the estimated mean within individual change with time. ${ }^{*} \mathrm{p}<0.05,{ }^{* * *} \mathrm{p}<$ 0.001 compared with the GH-deficient group. Reproduced with permission from Hulthen et al. [30]: ${ }^{\odot}$ The Endocrine Society. 
responses [37]. The variability in persistence of GHD on repeat testing in these patients appears to depend not only on the type of test and the definition of GHD used in various studies, but also on whether GHD was isolated or associated with other pituitary hormonal deficits or organic disease. What is clear is that most short children treated with $\mathrm{GH}$ when retested as adults do not have classical severe GHD as previously defined as a cut-off point lower than $3 \mu \mathrm{g} / \mathrm{l}$ after insulin-induced hypoglycaemia $[38,39]$. Thus, the key question is which children, as young adults, should be retested to determine whether GH therapy should be continued?

In one of the few studies that included normal healthy controls, 62 young adults with CO GHD were retested using a $\mathrm{GH}$-releasing hormone (GHRH)-arginine test and their response compared with that of 48 age-matched, normal participants to the same test [40]. The third centile for normal response for this test was $16.5 \mu \mathrm{g} / \mathrm{l}$ and the first centile was $9.0 \mu \mathrm{g} / \mathrm{l}$. Based on a definition of GHD as a response less than the third centile, all patients with organic pituitary disease were confirmed to have GHD with a mean GH response of $2.8 \pm 0.8 \mu \mathrm{g} / \mathrm{l}$, while $65 \%$ of the idiopathic $\mathrm{GH}$-deficient patients (mean response 18.6 $\pm 4.7 \mu \mathrm{g} / \mathrm{l}$ ), and no patients from the GH neurosecretory dysfunction group (mean response $31.3 \pm 1.6 \mu \mathrm{g} / \mathrm{l}$ ) were confirmed to be GH deficient. With respect to the first centile limit of $\mathrm{GH}$ response (i.e. $9.0 \mu \mathrm{g} / \mathrm{l}$ ), retesting confirmed severe GHD in 94 and 52\% of patients with organic or isolated GHD, respectively.

In another study, the $\mathrm{GH}$ response to an insulin tolerance test (ITT) was re-evaluated in 69 adult patients with CO GHD. Normal responses were defined from 38 healthy individuals using the GHRH-pyridostigmine (PD) test and an ITT [41]. In 39 of the 69 patients (56\%), the GH response was less than $10 \mu \mathrm{g} / 1$ to the GHRH + PD test and in 21 of these 39 patients, the mean GH response to the ITT was $1.9 \pm 1.7 \mu \mathrm{g} / \mathrm{l}$, thus confirming severe GHD in these patients. Those patients with a GH response greater than $10 \mu \mathrm{g} / 1$ to GHRH + PD had a mean $\mathrm{GH}$ response to ITT of $21.1 \pm 9.3 \mu \mathrm{g} / \mathrm{l}$.

In a large multi-centre study of 817 patients, the positive predictive value for severe GHD of the number of associated pituitary hormone deficiencies and a low serum IGF-I level was examined [42]. GH testing was performed using 11 different methods, and thus, severe GHD was defined as a GH response less than $2.5 \mu \mathrm{g} / 1$. The study revealed that the positive predictive values for severe GHD of the presence of three or more associated pituitary hormone deficiencies or a low serum level of IGF-I, defined according to the competitive binding radioimmunoassay used in the study, was greater than $95 \%$. Whether other IGF-I assays would reveal comparative predictive results remains unclear, but warrants further investigation. Based on available data, the use of serum IGF-I alone to predict severe GHD cannot be recommended. Nevertheless, adding examination of serum IGF-I and IGF-binding protein 3 levels to GH testing may provide some further information regarding the integrity of the IGF-I and GH axes [37].

These various studies demonstrate the intrinsic problems associated with the diagnosis of GHD, including the different criteria for diagnosis and wide variety of provocative tests available. The consensus guidelines from the Growth Hormone Research Society recommend that insulin-induced hypoglycaemia should be used as a 'gold standard' test to diagnose severe GHD in adults [38, 43]. The ITT should only be performed in endocrine units experienced with the test. Alternative provocative tests of GH secretion may be useful, but require validation with appropriate test-specific cut-off values [44].

It is difficult to ascertain the exact rate of continued severe GHD from childhood into adulthood. Those with organic disease and multiple pituitary hormone deficiencies who had severe GHD during childhood will, most probably, remain so during adulthood and in general do not require retesting. It is less clear whether children with moderate GHD may develop persistent severe GHD because few studies have carefully followed such children with retesting as adults. Some children with previous cranial irradiation and moderate GHD diagnosed during childhood may, however, develop worsening GH reserve and severe GHD [45]. The high incidence ( $70 \%$ or more in some studies) of normal GH responses to retesting in patients with idiopathic or isolated GHD necessitates retesting in this diagnostic group. Those with organic disease, long-standing multiple pituitary hormone deficiency and documented molecular defects in the GH-IGF system could be excluded from testing [43].

\section{Management Issues of GH Deficiency after Final Height Is Reached}

Although GH has been approved as a therapeutic agent for adult GHD in most Western societies, its availability is limited in many countries because of financial and insurance restraints, and uncertainty about the long-term cost-benefit of such treatment. With the increasing evidence of the beneficial effects of GH replacement therapy for patients with severe adult GHD, it is anticipated that 
GH may become more readily available. Nevertheless, if GH therapy is discontinued because of its unavailability or patient desire to stop, an evaluation should be undertaken of the metabolic and biochemical consequences and the possible psychosocial effects of withdrawing GH. In this situation, measurement of changes in body composition, bone density, monitoring of IGF-I levels and adequate assessment of quality of life may provide valuable information to the patient and clinician about the individual consequences of GHD. This may aid the patient and the patient's physician in reaching a considered decision regarding whether to recommence GH therapy.

Paediatric and adult endocrinologists from Scandinavia, a region where $\mathrm{GH}$ for adult replacement therapy is readily available, recently discussed $\mathrm{GH}$ treatment into adulthood at an interactive workshop. Their recommendations advocated the continuation of $\mathrm{GH}$ replacement in adolescents into adulthood only when adequate measures have been performed to establish persistent severe GH deficiency [46]. It was emphasized that the paediatricians, at the start of GH treatment in children, should make it clear that GH replacement might continue into adulthood. Close collaboration between paediatric and adult endocrine specialists is mandatory for an efficient organization to be built based on local traditions, expertise and geographical considerations.

\section{Long-Term Safety of Continuing Long-Term GH Replacement}

Does GH treatment increase the risk of recurrence of cancer or the development of de novo cancers? The available data suggest that there is no increased risk of cancer during or after $\mathrm{GH}$ treatment and that GH therapy is therefore considered safe [47, 48].

In one of the best controlled studies, involving 180 children with brain tumours who received GH and 891 survivors not treated with GH, Swerdlow et al. [49] showed that the relative risk of first tumour recurrence and death was actually higher in the group not treated with GH. Nevertheless, data from a recent widely discussed retrospective study in 1,848 adults who had received human pituitary GH between 1959 and 1985 showed a small but significant increase in the incidence of cancer when these patients were re-evaluated between 1995 and 2000 [50]. Although this study did find an overall increased incidence of various cancers and a threefold increased mortality, the actual number of extra cancers was very small. This included only two extra cases of colo- rectal cancer (one patient may have had a familial predisposition). The authors themselves point out that these results are clearly preliminary and that the rate of cancer in an untreated group of GH-deficient patients is not known. The relatively small cohort and small numbers of patients affected with cancer may therefore have inadvertently skewed the results. Thus, larger and longer-term studies are clearly warranted to clarify this important question about the association, if any, between GH replacement therapy and cancer.

Similar quality data and follow-up is also missing for de novo cancers in adults with GHD during long-term GH replacement therapy. Current data suggest, however, that adults with pituitary adenoma may have an increased risk of other neoplasia. A retrospective survey compared the rate of neoplasia in patients with non-functional pituitary adenoma with that in the general population [51]. The investigators found an increased incidence of cancer in 151 patients with non-functional pituitary adenoma compared with the expected incidence in the general population. In a large study including all individuals with pituitary tumours included in the Swedish Cancer Registry between 1958 and 1991, an excessive mortality from all tumours (pituitary excluded) and malignant tumours of the brain was found [52]. These data indicate, therefore, that other forms of cancer may be associated with pituitary tumours or their treatment. Current recommendations for cancer prevention and early detection in the general population should therefore be implemented in adults and adolescents who receive $\mathrm{GH}$ replacement therapy. In addition, pituitary imaging should be performed before and on a regular basis during $\mathrm{GH}$ treatment in patients with underlying hypothalamic-pituitary neoplasm [47].

A retrospective analysis by Cutfield et al. of the KIGS (Pharmacia International Growth Database) database of 23,333 children who received $\mathrm{GH}$ treatment demonstrated abnormal glucose tolerance in 85 children $(0.36 \%)$ [53]. While there was no increase in the incidence of type 1 diabetes mellitus, the incidence of type 2 diabetes mellitus ( 34 cases per 100,000 years of GH treatment) was sixfold higher than reported in two large diabetes mellitus epidemiological studies of children. Based on this observation, the authors concluded that the GH therapy might have hastened the onset of type 2 diabetes mellitus in children with a predisposition to develop diabetes. Whether these data can be extrapolated to adult $\mathrm{GH}$ replacement therapy where the doses of GH are much lower is not known. Present data show that with commencement of $\mathrm{GH}$ replacement in adults, there is only a transient re- 
duction in insulin sensitivity [54] with no adverse effects on glucose metabolism after 5 years of treatment, even with reduced serum levels of insulin and triglycerides [55].

\section{Conclusion}

GH replacement therapy is considered to be safe and effective in transition patients with documented severe GHD. Thus, the overall evidence strongly suggests that GH therapy should be continued after attainment of final adult height. The consequences of CO GHD are more severe and may take years to normalize, so the safe duration of a break from GH treatment during adolescence is not known. We must acknowledge that all adolescents cannot be offered continued treatment. In this situation, it is recommended that follow-up clinical, psychosocial, metabolic and biochemical evaluations should be performed on a regular basis. Such studies should be performed where possible within a research study protocol to attain greater understanding and prospective data on the consequences of discontinuation of GH treatment, as relatively few prospective data exist. Studies of this type should, if possible, incorporate the study of adolescents documented with moderate-severe GHD or normal GH secretion on retesting. Continuing treatment with $\mathrm{GH}$ should be based on the individual optimization of the $\mathrm{GH}$ dose [56, 57], together with careful surveillance and management of other pituitary hormone deficiencies and underlying disease, all performed by an endocrinologist specializing in the field.

\section{References}

1 Borges O: Isometric and isokinetic knee extension and flexion torque in men and women aged 20-70. Scand J Rehab Med 1989;21:4553.

2 Recker RR, Davies KM, Hinders SM, Heaney RP, Stegman MR, Kimmel DB: Bone gain in young adult women. JAMA 1992;268:24032408.

3 Rosen T, Bengtsson BA: Premature mortality due to cardiovascular diseases in hypopituitarism. Lancet 1990;336:285-288.

4 Tomlinson JW, Holden N, Hills RK, Wheatley K, Clayton RN, Bates AS, Sheppard MC, Stewart PM: Association between premature mortality and hypopituitarism. West Midlands Prospective Hypopituitary Study Group. Lancet 2001;357:425-431.

5 Bengtsson BA, Eden S, Lonn L, Kvist H, Stokland A, Lindstedt G, Bosaeus I, Tolli J, Sjostrom L, Isaksson OG: Treatment of adults with growth hormone $(\mathrm{GH})$ deficiency with recombinant human GH. J Clin Endocrinol Metab 1993;76:309-317.

6 Salomon F, Cuneo RC, Hesp R, Sonksen PH: The effects of treatment with recombinant human growth hormone on body composition and metabolism in adults with growth hormone deficiency. N Engl J Med 1989;321: 1797-1803.

7 Rosen T, Wiren L, Wilhelmsen L, Wiklund I, Bengtsson BA: Decreased psychological wellbeing in adult patients with growth hormone deficiency. Clin Endocrinol 1994;40:111-116.

8 Bengtsson BA, Johannsson G: Effect of growthhormone therapy on early atherosclerotic changes in GH-deficient adults. Lancet 1999; 353:1898-1899.
9 Jorgensen JO, Pedersen SA, Thuesen L, Jorgensen J, Ingemann-Hansen T, Skakkebaek NE, Christiansen JS: Beneficial effect of growth hormone treatment in GH-deficient adults. Lancet 1989;i:1221-1225.

10 De Boer H, Blok GJ, Voerman HJ, De Vries PMJ, Van Der Veen EA: Body composition in adult growth hormone-deficient men, assessed by anthropodometry and bioimpedance analysis. J Clin Endocrinol Metab 1992;75:833837.

11 Attanasio AF, Lamberts SW, Matranga AM, Birkett MA, Bates PC, Valk NK, Hilsted J, Bengtsson BA, Strasburger CJ: Adult growth hormone $(\mathrm{GH})$-deficient patients demonstrate heterogeneity between childhood onset and adult onset before and during human $\mathrm{GH}$ treatment. Adult Growth Hormone Deficiency Study Group. J Clin Endocrinol Metab 1997; 82:82-88.

12 Johannsson G, Grimby G, Sunnerhagen KS, Bengtsson BA: Two years of growth hormone $(\mathrm{GH})$ treatment increases isometric and isokinetic muscle strength in GH-deficient adults. J Clin Endocrinol Metab 1997;82:2877-2884.

13 Kaufman JM, Taelman P, Vermeulen A, Vandeweghe M: Bone mineral status in growth hormone-deficient males with isolated and multiple pituitary deficiencies of childhood onset. J Clin Endocrinol Metab 1992;74:118-123.

14 Rosen T, Hansson T, Granhed H, Szucs J, Bengtsson BA: Reduced bone mineral content in adult patients with growth hormone deficiency. Acta Endocrinol 1993;129:201-208.

15 Cittadini A, Cuocolo A, Merola B, Fazio S, Sabatini D, Nicolai E, Colao A, Longobardi S, Lombardi G, Sacca L: Impaired cardiac performance in GH-deficient adults and its improvement after GH replacement. Am J Physiol 1994;267:E219-E225.
16 Longobardi S, Cuocolo A, Merola B, Di Rella F, Colao A, Nicolai E, Cardei S, Salvatore M, Lombardi G: Left ventricular function in young adults with childhood and adulthood onset growth hormone deficiency. Clin Endocrinol (Oxf) 1998;48:137-143.

17 Johannsson G, Bjarnason R, Bramnert M, Carlsson LM, Degerblad M, Manhem P, Rosen $\mathrm{T}$, Thoren $\mathrm{M}$, Bengtsson BA: The individual responsiveness to growth hormone $(\mathrm{GH})$ treatment in GH-deficient adults is dependent on the level of $\mathrm{GH}$ binding protein, body mass index, age and gender. J Clin Endocrinol Metab 1996;81:1575-1581.

18 Janssen YJ, Frolich M, Roelfsema F: A low starting dose of genotropin in growth hormonedeficient adults. J Clin Endocrinol Metab 1997;82:129-135.

19 Saggese G, Baroncelli GI, Bertelloni S, Barsanti $\mathrm{S}$ : The effect of long-term growth hormone $(\mathrm{GH})$ treatment on bone mineral density in children with $\mathrm{GH}$ deficiency. Role of $\mathrm{GH}$ in the attainment of peak bone mass. J Clin Endocrinol Metab 1996;81:3077-3083.

20 Attanasio AF, Howell S, Bates PC, Frewer P, Chipman J, Blum WF, Shalet SM: Body composition, IGF-I and IGFBP-3 concentrations as outcome measures in severely GH-deficient (GHD) patients after childhood GH treatment: a comparison with adult onset GHD patients. $\mathrm{J}$ Clin Endocrinol Metab 2002;87:3368-3372.

21 Koranyi J, Svensson J, Gotherstrom G, Sunnerhagen KS, Bengtsson B, Johannsson G: Baseline characteristics and the effects of five years of $\mathrm{GH}$ replacement therapy in adults with GH deficiency of childhood and adult onset: a comparative, prospective study. J Clin Endocrinol Metab 2001;86:4693-4699. 
22 Rutherford OM, Jones DA, Round JM, Buchanan CR, Preece MA: Changes in skeletal muscle and body composition after discontination of growth hormone treatment in growth hormone deficient adults. Clin Endocrinol (Oxf) 1991;34:469-475.

23 Colle M, Auzerie J: Discontinuing of growth hormone therapy in growth-hormone-deficient patients: assessment of body fat mass using bioelectrical impedance. Horm Res 1993;39: 192-196.

24 Ogle GD, Moore B, Lu PW, Craighead A, Briody JN, Cowell CT: Changes in body composition and bone density after discontinuation of growth hormone therapy in adolescence: an interim report. Acta Peadiatr 1994;399(suppl): 3-7.

25 Johannsson G, Albertsson-Wikland K, Bengtsson BA: Discontinuation of growth hormone (GH) treatment: Metabolic effects in GH-deficient and GH-sufficient adolescent patients compared with control subjects. Swedish Study Group for Growth Hormone Treatment in Children. J Clin Endocrinol Metab 1999;84 4516-4524.

26 Porkka KV, Viikari JS, Taimela S, Dahl M, Akerblom HK: Age and gender specific serum lipid and apolipoprotein fractiles of Finnish children and young adults. The Cardiovascular Risk in Young Finns Study. Acta Paediatr 1994;83:838-848.

27 Ogle GD, Allen JR, Humphries IR, Lu PW, Briody JN, Morley K, Howman-Giles R, Cowell CT: Body-composition assessment by dualenergy x-ray absorptiometry in subjects aged 4-26 y. Am J Clin Nutr 1995;61:746-753.

28 Norrelund H, Vahl N, Juul A, Moller N, Alberti KG, Skakkebaek NE, Christiansen JS, Jorgensen JO: Continuation of growth hormone (GH) replacement in GH-deficient patients during transition from childhood and adulthood: a two-year placebo-controlled study. J Clin Endocrinol Metab 2000;85:1874-1881.

29 Norrelund H, Vahl N, Juul A, Moller N, Alberti KG, Skakkebaek NE, Christiansen JS, Jorgensen JO: Continuation of growth hormone (GH) therapy in GH-deficient patients during transition from childhood to adulthood: impact on insulin sensitivity and substrate metabolism. J Clin Endocrinol Metab 2000;85:19121917.

30 Hulthen L, Bengtsson BA, Sunnerhagen KS, Hallberg L, Grimby G, Johannsson G: GH is needed for the maturation of muscle mass and strength in adolescents. J Clin Endocrinol Metab 2001;86:4765-4770.

31 Colao A, Di Somma C, Spinelli L, Orio F, Lombardi G: The cardiovascular risk of GH-deficient adolescents. J Clin Endocrinol Metab 2002;87:3650-3655.

32 Fors H, Bjarnason R, Wiren L, AlbertssonWikland K, Bosaeus L, Bengtsson BA, Johannsson G: Currently used growth-promoting treatment of children results in normal bone mass and density. A prospective trial of discontinuing growth hormone treatment in adolescents. Clin Endocrinol (Oxf) 2001;55:617624.

GHD: Continuing GH Therapy in

Transition from Adolescence to Adult Life
33 Holmes SJ, Whitehouse RW, Swindell R, Economou G, Adams JE, Shalet SM: Further increase in forearm cortical bone mineral content after discontinuation of growth hormone replacement. Clin Endocrinol (Oxf) 1995;42: 3-7.

34 Drake WM, Carroll PV, Maher KT, Metcalfe KA, Shaw NJ, Camacho-Hubner C, Dunger DB, Chetham TD, Savage MO, Monson JP: Arrested bone mineralisation in GHD adolescents at final height. Growth Hormone IGF Res 2002;12:Abstract 018.

35 Gotherstrom G, Svensson J, Koranyi J, Alpsten M, Bosaeus I, Bengtsson B, Johannsson G: A prospective investigation of quality of life and psychological well-being following the discontinuation of growth hormone $(\mathrm{GH})$ treatment in adolescent patients who had GH deficiency during their childhood. J Clin Endocrinol Metab 2001;86:3494-3498.

36 Murray RD, Skillicorn CJ, Howell SJ, Lissett CA, Rahim A, Smethurst LE, Shalet SM: Influences on quality of life in GH deficient adults and their effect on response to treatment. Clin Endocrinol (Oxf) 1999;51:565-573.

37 Sizonenko PC, Clayton PE, Cohen P, Hintz RL, Tanaka T, Laron Z: Diagnosis and management of growth hormone deficiency in childhood and adolescence. Part 1: Diagnosis of growth hormone deficiency. Growth Hormone IGF Res 2001;11:137-165.

38 Hoffman DM, Nguyen TV, O’Sullivan AJ, Baxter RC, Ho KK: Diagnosis of growth hormone deficiency in adults. Lancet 1994;343: 1064-1068.

39 Consensus guidelines for the diagnosis and treatment of adults with growth hormone deficiency: Summary statement of the Growth Hormone Research Society workshop on Adult Growth Hormone Deficiency. J Clin Endocrinol Metab 1998;83:379-381.

40 Aimaretti G, Baffoni C, Bellone S, Di Vito L, Corneli G, Arvat E, Benso L, Camanni F, Ghigo E: Retesting young adults with childhood-onset growth hormone $(\mathrm{GH})$ deficiency with GH-releasing-hormone-plus-arginine test. J Clin Endocrinol Metab 2000;85:3693-3699.

41 Longobardi S, Merola B, Pivonello R, Di Rella F, Di Somma C, Colao A, Ghigo E, Camanni F, Lombardi G: Reevaluation of growth hormone $(\mathrm{GH})$ secretion in 69 adults diagnosed as $\mathrm{GH}-$ deficient patients during childhood. J Clin Endocrinol Metab 1996;81:1244-1247.

42 Hartman ML, Crowe BJ, Biller BM, Ho KK, Clemmons DR, Chipman JJ: Which patients do not require a $\mathrm{GH}$ stimulation test for the diagnosis of adult GH deficiency? J Clin Endocrinol Metab 2002;87:477-485.

43 Consensus guidelines for the diagnosis and treatment of growth hormone $(\mathrm{GH})$ deficiency in childhood and adolescence: Summary statement of the GH Research Society. J Clin Endocrinol Metab 2000;85:3990-3993.

44 Biller BM, Samuels MH, Zagar A, Cook DM, Arafah BM, Bonert V, Stavrou S, Kleinberg DL, Chipman JJ, Hartman ML: Sensitivity and specificity of six tests for the diagnosis of adult GH deficiency. J Clin Endocrinol Metab 2002;87:2067-2079.
45 Nicolson A, Toogood AA, Rahim A, Shalet SM: The prevalence of severe growth hormone deficiency in adults who received growth hormone replacement in childhood. Clin Endocrinol (Oxf) 1996;44:311-316.

46 Transition of GH-deficient patients from paediatric to adult endocrine care. International Growth Monitor 2001;12:29.

47 Critical evaluation of the safety of recombinan human growth hormone administration: Statement from the Growth Hormone Research Society. J Clin Endocrinol Metab 2001;86:18681870 .

48 Lawson Wilkins Pediatric Endocrine Society (LWPES) Writing Committee: Growth hormone treatment and neoplasia - coincidence or consequence? J Clin Endocrinol Metab 2002; 87:5351-5352.

49 Swerdlow AJ, Reddingius RE, Higgins CD, Spoudeas HA, Phipps K, Qiao Z, Ryder WD, Brada M, Hayward RD, Brook CG, Hindmarsh PC, Shalet SM: Growth hormone treatment of children with brain tumors and risk of tumor recurrence. J Clin Endocrinol Metab 2000;85:4444-4449.

50 Swerdlow AJ, Higgins CD, Adlard P, Preece MA: Risk of cancer in patients treated with human pituitary growth hormone in the UK, 1959-85: A cohort study. Lancet 2002;360: 273-277.

51 Popovic V, Damjanovic S, Micic D, Nesovic M, Djurovic M, Petakov M, Obradovic S, Zoric S, Simic M, Penezic Z, Marinkovic J: Increased incidence of neoplasia in patients with pituitary adenomas. The Pituitary Study Group. Clin Endocrinol (Oxf) 1998;49:441-445.

52 Nilsson B, Gustavsson-Kadaka E, Bengtsson BA, Jonsson B: Pituitary adenomas in Sweden between 1958 and 1991: Incidence, survival, and mortality. J Clin Endocrinol Metab 2000; 85:1420-1425.

53 Cutfield WS, Wilton $\mathrm{P}$, Bennmarker $\mathrm{H}, \mathrm{Al}-$ bertsson-Wikland $\mathrm{K}$, Chatelain $\mathrm{P}$, Ranke MB, Price DA: Incidence of diabetes mellitus and impaired glucose tolerance in children and adolescents receiving growth-hormone treatment. Lancet 2000;355:610-613.

54 Fowelin J, Attvall S, Lager I, Bengtsson BA: Effects of treatment with recombinant human growth hormone on insulin sensitivity and glucose metabolism in adults with growth hormone deficiency. Metabolism 1993;42:1443-1447.

55 Gotherstrom G, Svensson J, Koranyi J, Alpsten M, Bosaeus I, Bengtsson BA, Johannsson $\mathrm{G}$ : A prospective study of 5 years of $\mathrm{GH}$ replacement therapy in $\mathrm{GH}$-deficient adults: Sustained effects on body composition, bone mass, and metabolic indices. J Clin Endocrinol Metab 2001;86:4657-4665.

56 Johannsson G, Rosen T, Bengtsson BA: Individualized dose titration of growth hormone $(\mathrm{GH})$ during $\mathrm{GH}$ replacement in hypopituitary adults. Clin Endocrinol (Oxf) 1997; 47:571-581.

57 Drake WM, Coyte D, Camacho-Hubner C, Jivanji NM, Kaltsas G, Wood DF, Trainer PJ, Grossman AB, Besser GM, Monson JP: Optimizing growth hormone replacement therapy by dose titration in hypopituitary adults. J Clin Endocrinol Metab 1998;83:3913-3919. 